\title{
Examining the relationship between surface bioburden and frequently touched sites in Intensive Care
}

\author{
Adams $\mathrm{CE}^{1}$, Smith $\mathrm{J}^{2}$, Watson $\mathrm{V}^{1}$, Robertson $\mathrm{C}^{3-5}$, Dancer $\mathrm{SJ}^{2,6 *}$ \\ ${ }^{1}$ Dept. of Anaesthesia, Hairmyres Hospital, NHS Lanarkshire, UK \\ ${ }^{2}$ Dept. of Microbiology, Hairmyres Hospital, NHS Lanarkshire, UK \\ ${ }^{3}$ Dept. of Mathematics and Statistics, University of Strathclyde, Glasgow \\ ${ }^{4}$ Health Protection Scotland, Glasgow \\ ${ }^{5}$ International Prevention Research Institute, Lyon, France \\ ${ }^{6}$ School of Life, Sport and Social Sciences, Edinburgh Napier University, UK
}

\begin{abstract}
*Corresponding author: Dr S. J. Dancer, Dept. of Microbiology, Hairmyres hospital, East Kilbride, Lanarkshire G75 8RG

E-mail: stephanie.dancer@lanarkshire.scot.nhs.uk
\end{abstract}

Tel: +44-1355 585000; Fax: +44-1355 584350 


\section{Summary}

Aims: Critical care patients are at increased risk of infection. Near-patient surfaces act as reservoirs of microbial soil, which may contain pathogens. This study aimed to correlate soil levels with hand-touch frequency of near-patient sites in an Intensive Care Unit (ICU).

Methods: Five sites around each bed in a 10-bed ICU were screened for total microbial soil (cfu/cm2) and Staphylococcus aureus every month for ten months. Selected sites were infusion pump and cardiac monitor, left and right bedrails and bed table. Ten one hour covert audits of hand-touch frequency of these sites were performed in order to provide an average hand-touch count, which was modelled against soil levels obtained from microbiological screening.

Results: Seven of ten staphylococci were found in conjunction with gross contamination of a specific site $(p=0.005)$ and the same proportion from three most frequently touched sites (bedrails and bed table). There was a linear relationship between four sites demonstrating gross microbial contamination $(>12 \mathrm{cfu} / \mathrm{cm} 2)$ and mean number of hand-touch counts $(p=$ 0.08). The bed table was handled most but was not the most contaminated site. We suspected that customary placement of alcohol gel containers on bed tables may have reduced microbiological yield. Removing the gel from one table confirmed its inhibitory effect on microbial contamination after rescreening ( $19 \%$ vs. $50 \%>12 \mathrm{cfu} / \mathrm{cm}^{2}: \mathrm{p}=0.007$ ).

Conclusion: Surface bioburden at near-patient sites in ICU is associated with hand-contact frequencies by staff and visitors. This supports the need for targeted hygienic cleaning in a high-risk healthcare environment.

Key words: Hospital cleaning; ICU; Healthcare environment; Hand-touch sites; Microbial reservoirs 


\section{Introduction}

The hospital environment is habitually contaminated with micro-organisms and may thus play a role in the spread of pathogens such as Staphylococcus aureus (MSSA) and methicillin-resistant S.aureus (MRSA). ${ }^{1}$ These pathogens are predominantly located at sites adjoining the patient's bedside and could be transmitted to patients via contaminated hands of healthcare workers. ${ }^{2-5}$ Hospitals promote the importance of hand hygiene but staff do not always clean their hands when they should and near-patient surfaces do not always receive adequate cleaning. ${ }^{6,7}$

Patients in an intensive care unit (ICU) are at increased risk of acquiring a nosocomial infection compared with those on a general ward. Firstly, compromised patients are at risk from their own endogenous organisms, and secondly, cleaning frequencies of high-risk surfaces may not be sufficient to impede the risk of repeated recontamination with pathogens. ${ }^{8}$ While hand hygiene remains the cornerstone of infection control, frequently touched sites inevitably host reservoirs of microbes. ${ }^{4,9,10}$

The objective of this study was to examine which near-patient sites are most frequently handled in the ICU and whether there is a relationship between hand-touch frequencies and microbial soil found at those sites, including presence of MSSA and MRSA. Recognition of this association would help prioritise the cleaning of near-patient sites in the ICU, as well as facilitating review of current cleaning frequencies.

\section{Methods}

\section{Setting}

The study unit is a ten bed adult ICU in a district general hospital. Five beds are designated for ventilated patients and the remainder for patients who do not require mechanical ventilation. Each ventilated patient is nursed on a 1:1 basis, with highly dependent patients also provided with their own nurse or shared with another patient as appropriate.

Bed occupancy within the ICU ranges from $50-100 \%$, with daily turnover of at least 1-5 patients. Cases include multiple trauma, cardiac conditions, community-acquired pneumonia and those who require support following routine or emergency surgery. The unit also manages immunosuppressed patients, acute sepsis and alcohol and drug poisoning. Each bed has an adjoining table positioned at the end for patient charts and a bottle of alcohol gel (Spirigel Complete ${ }^{\circledR}$; Ecolab, Cheshire, UK).

\section{Cleaning}

Domestic and nursing staff share responsibility for routine cleaning of general surfaces and clinical equipment. Domestic staff clean floors, toilets and general surfaces once daily and near-patient sites (furniture and equipment) are cleaned by nurses twice daily (once per 12 hour shift). Cleaning is detergent-based, with detergent wipes (Vernacare Tuffie ${ }^{\mathrm{TM}}$ wipes) 
used for clinical equipment and water and detergent $\left(\mathrm{Hospec}^{\mathrm{TM}}\right)$ for floors and general surfaces. Wipes are confined to one bed-space only, with one wipe allocated for each separate site before disposal. Bed-spaces of patients colonised or infected with hospital pathogens, either in the single isolation room or in the main body of the unit, are cleaned with bleach (Actichlor Plus ${ }^{\mathrm{TM}}$ ). All surfaces receive routine bleach cleaning every Sunday. After a patient is discharged, terminal cleaning of all surfaces within the bed-space is carried out in coordinated fashion between domestic and nursing staff. Environmental and hand hygiene audits are regularly carried out by Infection control nurses, with written reports fed back to staff and displayed outside ICU.

\section{Pilot study}

Hand touch sites chosen for investigation were selected following prior audit of hand touch frequency. Staff and visitors in the ICU were not aware that these audits were taking place, in order to obtain as accurate a representation of hand-touch frequency as possible. The five most commonly handled sites common to all ICU patients were: bed table, both bedrails and control panels of the IV infusion pump and cardiac monitor. Patients' ventilator tubing was also frequently touched but this site was excluded because not all patients are ventilated. The most common hand-touch sites identified from the pilot study were similar to those found previously on an acute ward in this, and unrelated, hospitals. ${ }^{11-13}$

One hand touch episode was recorded when the observer saw the fingertips and/or hand palm clearly touching a site; should the same person continue to touch that particular site then no further episodes were counted. If a person touched a site, moved away and touched something else, but then returned and retouched the original site, then a further hand touch episode was documented.

\section{Environmental screening}

Once the five most commonly handled surfaces were chosen, an unannounced standardised environmental screen was initiated. This occurred once per month for ten months and was conducted during the morning (Mon-Sat) before near-patient sites were cleaned.

Screening was performed using double sided dipslides (Hygiena Int., Watford, UK), coated with nutrient and staphylococcal selective (Baird Parker) agars. Each slide was systematically placed on the chosen site for 10 seconds with no screening overlap between the different agars. Pressure applied $\left(25 \mathrm{~g} / \mathrm{cm}^{2}\right)$ was pre-determined according to Griffith et al and screening performed by the same two study personnel. ${ }^{14}$ After sampling all five sites around each of the ten beds, dipslides were loosely capped and returned to the on-site laboratory for incubation (48-72 hours) at $35^{\circ} \mathrm{C}$ in $\mathrm{CO}_{2}$.

Growth on nutrient agar supplied total aerobic colony counts (ACC) per $\mathrm{cm}^{2}$ which were classified as follows: no growth (NG); scanty growth (SG) $<2.5 \mathrm{cfu} / \mathrm{cm}^{2}$; light growth (LG) 2.5 $12 \mathrm{cfu} / \mathrm{cm}^{2}$; moderate growth (MG) $12-40 \mathrm{cfu} / \mathrm{cm}^{2}$; and heavy growth $\left(>40 \mathrm{cfu} / \mathrm{cm}^{2}\right)$ and as 
previously defined. ${ }^{3,9,11}$ Selective agar highlighted potential coagulase-positive staphylococci, which were sub-cultured onto Staphylococcus aureus Identification (SAID) agar (Oxoid Ltd, UK), followed by automated susceptibility testing (VITEK) according to routine laboratory protocol. Hygiene standards have been proposed whereby ACC $>5$ $\mathrm{cfu} / \mathrm{cm}^{2}$ and/or presence of MSSA/MRSA at a hand-touch site indicates increased infection risk for patients. ${ }^{15}$

\section{Hand touch frequency audit}

One individual performed ten covert audits in total, each for 60 minutes duration, documenting the frequency with which each chosen site was touched by finger-tips and/or palm. The definition of each hand-touch episode was the same as for the pilot study and maintained throughout the audit. Activities performed behind curtains were excluded from the audit but this occurred infrequently at the study times (average 2 bed spaces for $5-10$ mins/hr). These audits were not done on the same day as microbiological screening, but were conducted Mon-Sat, between 10am-3pm, and included both staff and visitor practices.

\section{Statistical analysis}

All data were subjected to statistical analyses. Each of the five sites around 10 beds supplied an $\mathrm{ACC} / \mathrm{cm}^{2}$ categorised as indicated, along with data for presence or not of MSSA/MRSA. Each of the ten study days provided a series of results for $10 \times 5$ sites, ultimately giving data for 500 sites. The number of sites demonstrating gross contamination $\left(>12 \mathrm{cfu} / \mathrm{cm}^{2}\right)$ from all ten screening occasions was calculated and modelled against the average number of times a specific site was handled.

A Chi square test was used to test the association between hand touch site and ACC. Fishers test was used to test the equality of the proportion of MRSA/MSSA over the different levels of ACC and between ACC with, and without, alcohol gel on the table. The association between hand-touch frequency and ACC quantity was investigated using rank correlation tests.

\section{Results}

Staff touched study sites between an average of 6/hour (cardiac monitor) to 37/hour (bed table) (Table). There were occasional contributions from visitors, who often touched the bedrails, particularly those on the patient's left-hand-side. A range of microbial soil quantities were found from all five sites, with a greater proportion of samples from the cardiac monitor demonstrating no growth and highest levels of contamination ( $>40 \mathrm{cfu} / \mathrm{cm}^{2}$ ) from the bedrails $(p<0.0001)$.

Only one MRSA and nine MSSA isolates were recovered from 500 screened sites during the ten month study and these were found from all five sites ( $p=0.67$ )(Table). Four (including the single MRSA isolate) came from the left bedrail, two MSSA each from IV pump and bed 
table, and one MSSA isolate each from cardiac monitor and right bedrail. Seven of ten staphylococci were found in conjunction with gross contamination $\left(>12 \mathrm{cfu} / \mathrm{cm}^{2}\right)$ of a specific site $(p=0.005)$ and another seven were recovered from the three most frequently touched sites (bedrails and bed table).

There is a positive association between hand touch frequency and gross contamination ( $>12$ $\mathrm{cfu} / \mathrm{cm}^{2}$ ) for four of the study sites (cardiac monitor, infusion pump and bedrails), providing a spearman correlation of $1(p=0.08)$ (Table; Figure 1$)$. However, the most highly touched site, the bed table, gave anomalous bioburden results (unexpectedly low contamination), bringing the correlation down to a non-significant $0.7(p=0.23)$. Since alcohol gel containers are habitually placed on the bed tables, it was postulated that staff engaging in hand hygiene may then touch the table, with transfer of gel from hand to table surfaces destined for microbiological sampling. This was witnessed during the hand-touch audit. Less likely is release of micro-aerosol when the plunger is depressed, which might have reduced the cultural yield (Figure 2). The alcohol content ( $85 \mathrm{~g}$ ethanol per $100 \mathrm{~g}$ ) is sufficient to inhibit or kill microbes on environmental surfaces. There were twice as many slides yielding 'no growth' from the bed table as there were from each of the two bedrails (Table).

This hypothesis was investigated, by removing the alcohol gel from one bed table (Bed 3) and repeating microbiological screening during unannounced visits. The bed space chosen still permitted easy access for alcohol gel for staff at least one metre away from the end of bed table being screened. Of ten dipslides used for additional sampling, 5 (50\%) yielded $>12$ $\mathrm{cfu} / \mathrm{cm}^{2}$, which was higher than the proportion from either bedrail (37\%; 39\%). Comparing original bed table ACC quantity against the data from additional screening results in $19 \%$ vs. $50 \%>12 \mathrm{cfu} / \mathrm{cm}^{2}(\mathrm{p}=0.007)$. This suggests that placing alcohol gel on the bed table affected the yield of microbial soil when sampling (Figure). It also corroborates the apparent association between frequency of hand touch and microbial soil at study sites.

\section{Discussion}

This study has shown that frequently touched near-patient sites in the critical care environment are more likely to be heavily contaminated with microbial soil. There also appears to be a quantitative relationship between the number of times a surface is handled and the amount of aerobic microbial soil retrieved from that surface. This offers a tangible method for measuring infection risk for patients as well as highlighting the importance of cleaning these sites on a frequent basis. The study also found that the yield from microbiological sampling of surfaces can be influenced by positioning of hand hygiene gel products in the ICU.

Although the numbers are small, isolation of MSSA and/or MRSA from a hand touch site seems to be more likely if there is associated heavy microbial soil. This relationship has been described previously. ${ }^{3}$ Since four of ten staphylococci, including the single MRSA isolate, were recovered from the left bedrail, it may be pertinent to note that this site was the site 
most frequently touched by visitors; staff usually approached the patient from the right and were more likely to handle the right bedrail. ${ }^{13}$ Visitor hand hygiene remains an unexplored issue for infection control throughout the hospital.

Frequent touch near-patient sites would benefit from targeted hygienic cleaning in the critical care environment. ${ }^{1,3}$ This may not be a priority in modern ICUs, especially if there are staff shortages or the unit is busy. Any attempt to remove soil will also be compromised by rapidity of recontamination, since some sites become positive for MRSA within one hour after cleaning. ${ }^{16}$ It is tempting to apply powerful disinfectants to these sites, especially those with prolonged effects. However, surface recontamination still occurs even after comprehensive cleaning with disinfectants, including exposure to hydrogen peroxide. ${ }^{17,18}$ Ultimately, physical removal of bioburden may be just as effective as disinfectants for controlling microbial soil. ${ }^{5,8}$ More work is required to clarify this, because aside from cost issues, detergents are less toxic and unlikely to promote acquisition of antimicrobial resistance genes among environmental bacteria. ${ }^{19}$

Another remedy for contaminated surfaces might be the application of antimicrobial paint onto frequent touch surfaces. ${ }^{20}$ Coatings with prolonged biocidal activity might be a useful adjunct for controlling recontamination. This would relieve the pressure on both surface cleaning and hand hygiene, provided such coatings demonstrate uniform and long-term activity.

In conclusion, this study suggests that there is a relationship between frequently touched sites beside critical care patients and the quantity of microbial soil at those sites. Knowledge and understanding of this relationship might help prioritise cleaning, and its frequency, of these and other sites in the ICU. Placement of hand hygiene gels could affect cultural yield if surfaces beside the gel are sampled.

\section{Acknowledgements}

Grateful thanks are due to Mr Raymond Hamill, Research and Development Manager, ICU staff and Andrew Craig (Medical Illustration), Hairmyres hospital, NHS Lanarkshire.

\section{Funding}

This study was funded by NHS Lanarkshire, with dipslides courtesy of UNISON.

\section{Disclosures}

No relevant disclosures to report for any of the authors. 


\section{Figure legends}

Figure 1: Hand touch frequency and gross microbial soil for five near patient sites on ICU

NB. Average hand-touch frequency/site/hr following ten observational audits;

Each site $(n=5)$ in ten bed spaces was screened on ten occasions (see Table);

Gross microbial soil defined as no. of screens exceeding $12 \mathrm{cfu} / \mathrm{cm}^{2}$;

ICU: Intensive Care Unit

Figure 2: Study ICU showing bottle of alcohol gel on a bed table

ICU: Intensive Care Unit

\section{References}

1. Dancer SJ. Importance of the environment in meticillin-resistant Staphylococcus aureus acquisition: the case for hospital cleaning. Lancet Infect Dis 2008; 8: 101-113.

2. Bhalla A, Pultz NJ, Gries, DM, et al. Acquisition of nosocomial pathogens on hands after contact with environmental surfaces near hospitalised patients. Infect Control Hosp Epidemiol 2004; 25: 164-167.

3. Dancer SJ, White L, Robertson C. Monitoring environmental cleanliness on two surgical wards. Int J Environ Hygiene 2008; 18: 357-364.

4. Hayden MK, Blom DW, Lyle EA, Moore CG, Weinstein RA. Risk of hand or glove contamination after contact with patients colonized with vancomycin-resistant enterococcus or the colonized patients' environment. Infect Control Hosp Epidemiol 2008; 29: 149-54.

5. Dancer SJ. The role of environmental cleaning in the control of hospital-acquired infection. J Hosp Infect 2009; 73: 378-385.

6. Dancer SJ. Control of transmission of infection in hospitals requires more than clean hands. Infect Control Hosp Epidemiol 2010; 31: 958-960.

7. Carling PC, Briggs J, Hylander D, Perkins J. An evaluation of patient area cleaning in 3 hospitals using a novel targeting methodology. Am J Infect Control 2006; 34: 513-9.

8. Dancer SJ. Controlling hospital-acquired infection: focus on the role of the environment and new technologies for decontamination. Clin Microbiol Rev 2014; 27: 665-90.

9. White L, Dancer SJ, Robertson C, MacDonald J. Are hygiene standards useful in assessing infection risk? Am J Infect Control 2008; 36: 381-384. 
10. Russotto V, Cortegiani A, Raineri SM, Giarratano A. Bacterial contamination of inanimate surfaces and equipment in the intensive care unit. J Intensive Care 2015; 3: 1-8.

11. Bogusz A, Stewart M, Hunter J, et al. How quickly do hospital surfaces become contaminated after detergent cleaning? Healthcare Infect 2013; 18: 3-9.

12. Huslage K, Rutala WA, Sickbert-Bennett E, Weber DJ. A quantitative approach to defining "High-Touch" surfaces in hospitals. Infect Control Hosp Epidemiol 2010; 31: 850-853.

13. Cheng VCC, Chau PH, Lee WM, et al. Hand-touch contact assessment of high-touch and mutual-touch surfaces among healthcare workers, patients, and visitors. $J$ Hosp Infect 2015; 90: 220-25.

14. Griffith CJ, Obee P, Cooper RA, Burton NF, Lewis M. The effectiveness of existing and modified cleaning regimens in a Welsh hospital. J Hosp Infect 2007; 66: 352-59.

15. Dancer SJ. How do we assess hospital cleaning? A proposal for microbiological standards for surface hygiene in hospitals. J Hosp Infect 2004; 56: 10-15.

16. Aldeyab MA, McElnay JC, Elshibly SM, et al. Evaluation of the efficacy of a conventional cleaning regimen in removing methicillin-resistant Staphylococcus aureus from contaminated surfaces in an intensive care unit. Infect Control Hosp Epidemiol 2009; 30: 304-306.

17. Stewart M, Bogusz A, Hunter J, et al. Microbiological effect of cleaning near-patient sites with electrolysed water. Infect Control Hospital Epidemiol 2014; 35: 1505-10.

18. Hardy KJ, Gossain S, Henderson N, et al. Rapid recontamination with MRSA of the environment of an intensive care unit after decontamination with hydrogen peroxide vapour. J Hosp Infect 2007; 66: 360-368.

19. Sattar S. Promises and pitfalls of recent advances in chemical means of preventing the spread of nosocomial infections by environmental surfaces. Am J Infect Control 2010; 38: S34-S40.

20. Dancer SJ. Do's and Don'ts for hospital cleaning. Curr Opin Infect Dis 2016; 29: 415423. 
Table: Microbial contamination, MSSA/MRSA and hand touch frequency of five near-patient sites on ten-bedded ICU following ten screens

\begin{tabular}{|c|c|c|c|c|c|c|c|c|}
\hline Site & $\begin{array}{l}\text { No } \\
\text { Growth }\end{array}$ & $\begin{array}{l}\text { Scanty } \\
\text { Growth } \\
<2.5 \\
\mathrm{cfu} / \mathrm{cm}^{2}\end{array}$ & $\begin{array}{l}\text { Light } \\
\text { Growth } \\
>2.5-12 \\
\mathrm{cfu} / \mathrm{cm}^{2}\end{array}$ & $\begin{array}{l}\text { Moderate } \\
\text { Growth } \\
>12-40 \\
\mathrm{cfu} / \mathrm{cm}^{2}\end{array}$ & $\begin{array}{l}\text { Heavy } \\
\text { Growth } \\
>40 \mathrm{cfu} / \mathrm{cm}^{2}\end{array}$ & $\begin{array}{l}\text { MSSA } \\
\text { MRSA } \\
\text { Total }\end{array}$ & $\begin{array}{l}\text { Gross soil } \\
>12 \\
\mathrm{cfu} / \mathrm{cm}^{2}\end{array}$ & $\begin{array}{l}\text { Hand touch } \\
\text { frequency } \\
\text { (average 10x1 hr } \\
\text { audits) }\end{array}$ \\
\hline $\begin{array}{l}\text { Infusion } \\
\text { Pump } \\
n=100\end{array}$ & 16 & $\begin{array}{l}47 \\
\text { MSSA }\end{array}$ & 22 & $\begin{array}{l}13 \\
\text { MSSA }\end{array}$ & 2 & 2 & 15 & 9 \\
\hline $\begin{array}{l}\text { Cardiac } \\
\text { Monitor } \\
n=100\end{array}$ & 45 & 28 & $\begin{array}{l}16 \\
\text { MSSA }\end{array}$ & 9 & 2 & & 11 & 6 \\
\hline $\begin{array}{l}\text { Right } \\
\text { Bedrail } \\
n=100\end{array}$ & 6 & 38 & 17 & 27 & $\begin{array}{l}12 \\
\text { MSSA }\end{array}$ & 1 & 39 & 20 \\
\hline $\begin{array}{l}\text { Bed Table } \\
n=100\end{array}$ & 13 & 35 & $\begin{array}{l}33 \\
\text { MSSA }\end{array}$ & $\begin{array}{l}16 \\
\text { MSSA }\end{array}$ & 3 & 2 & 19 & 37 \\
\hline $\begin{array}{l}\text { Left } \\
\text { Bedrail } \\
n=100\end{array}$ & 6 & 31 & 26 & 25 & $\begin{array}{l}12 \\
\text { MSSA \& } \\
\text { MRSA }\end{array}$ & 4 & 37 & 16 \\
\hline
\end{tabular}

Key: MSSA: methicillin-susceptible S. aureus; MRSA: methicillin-resistant S.aureus

NB. Bed table 3's results from ten additional screens were:

NG: 1, SG: 5, LG: 2, MG: 2, HG: 0

Therefore, two occasions when the table yielded gross contamination $>12 \mathrm{cfu} / \mathrm{cm}^{2}(20 \%)$.

Repeat sampling $(n=10)$ after removal of alcohol gel:

NG: 0, SG: 2, LG: 3, MG: 3, HG: 2

Thus, five occasions when the table yielded gross contamination $>12 \mathrm{cfu} / \mathrm{cm}^{2}(50 \%)$. 


\section{Figure 1: Hand touch frequency and gross microbial soil for five near patient sites on ICU}

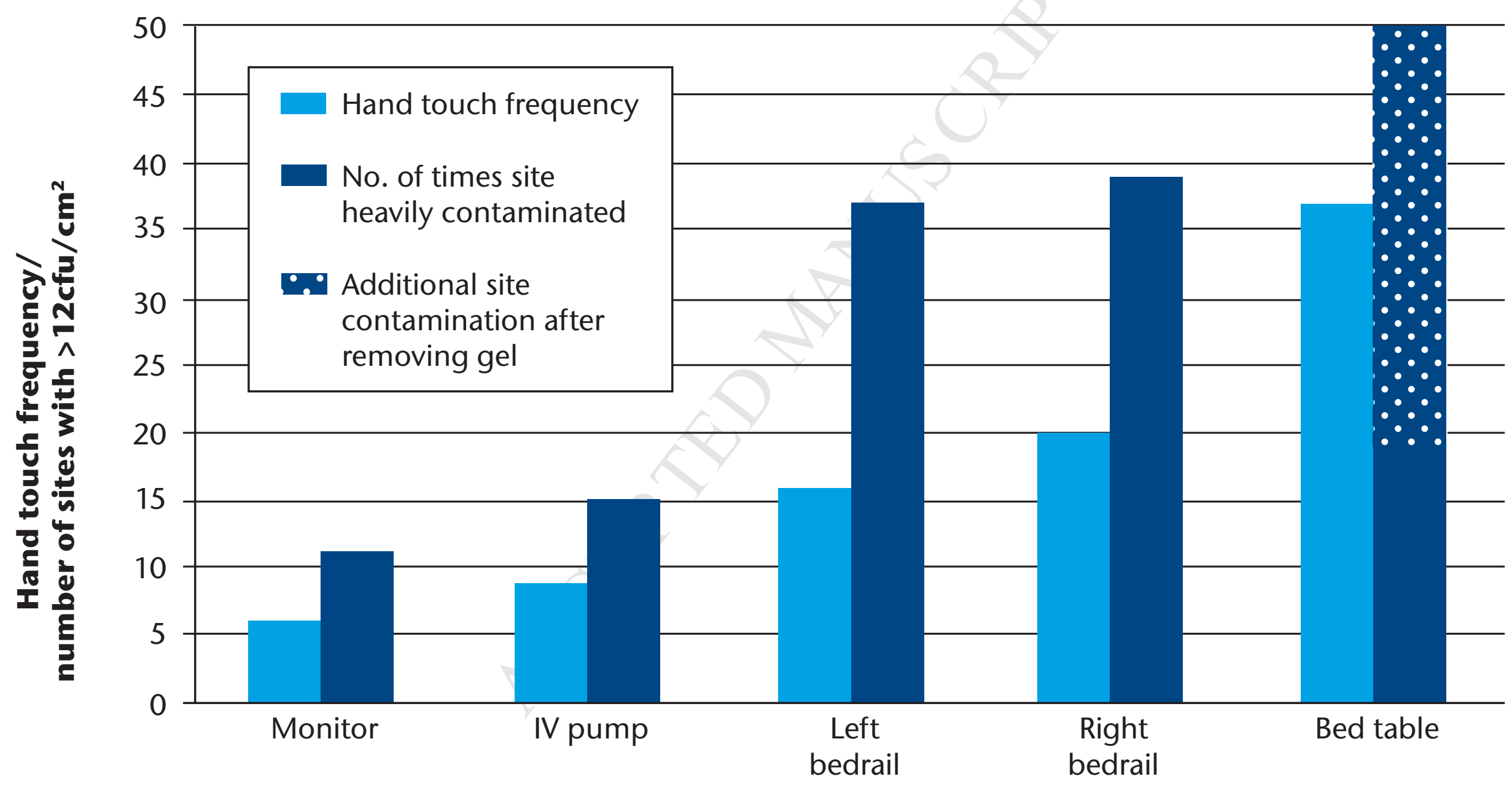

Five hand-touch points on ICU 


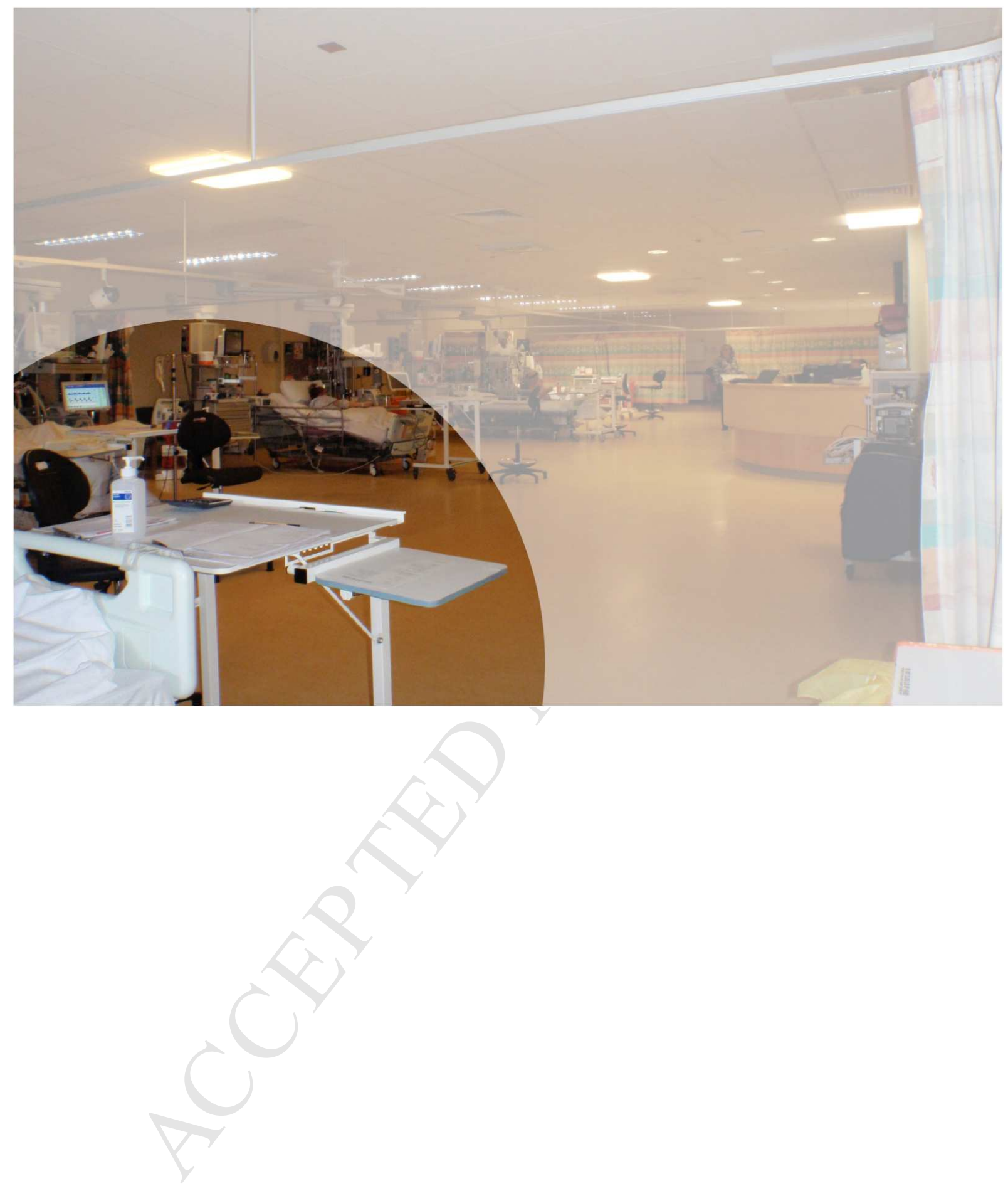

